\title{
Retraction Note: Coastal atmospheric climate and political teaching of sustainable development based on GIS
}

\author{
Jingjing Qin ${ }^{1}$
}

Published online: 12 November 2021

C) Saudi Society for Geosciences 2021

Retraction Note: Arabian Journal of Geosciences (2021) 14: 1151 https://doi.org/10.1007/s12517-021-07460-1

The Editor-in-Chief and the Publisher have retracted this article because the content of this article is nonsensical. The peer review process was not carried out in accordance with the Publisher's peer review policy. The author disagrees with this retraction.

The original article can be found online at https://doi.org/10.1007/ s12517-021-07460-1.

Jingjing Qin

qinjjnice@163.com

1 School of Marxism, Hainan Normal University, Haikou 571158, Hainan, China 